\title{
Populismo nos partidos políticos portugueses \\ - Os programas eleitorais de 2019
}

Populism in the portuguese political parties - The 2019 party manifestos

\section{João Palhau'}

\section{Patrícia Silva ${ }^{2}$}

\section{Edna Costa ${ }^{3}$}

Resumo: Portugal tem sido sistematicamente descrito como uma exceção em relação à onda de crescimento de populismo (particularmente, de direita) na Europa. Este artigo visa reavaliar esta tese considerando o contexto das Eleições Legislativas de 2019. Com base numa análise de conteúdo de programas eleitorais, procuramos identificar, medir e caraterizar a presença de dimensões de populismo nas propostas políticas dos partidos. Além disso, este artigo explora as interações entre as dimensões de populismo e outras posições partidárias. Os nossos resultados sugerem que os programas eleitorais são altamente impermeáveis à saliência de populismo, mesmo considerando o partido de direita radical populista que obteve assento parlamentar. Foi identificada uma correlação positiva entre a saliência de populismo e o grau de radicalismo ideológico.

Palavras-chave: Populismo; Portugal; partidos políticos; eleições 2019; programas eleitorais.

Abstract: Portugal has been systematically described as an exception to the wave of (right-wing) populism growth in Europe. This article aims to re-examine this claim considering the context of the Portuguese 2019 legislative elections. Drawing on content analysis of party manifestos, we seek to identify, measure, and characterize the presence of populist dimensions in parties' proposals. Moreover, the article explores the interactions between populist dimensions and other party policies. Our findings suggest that parties' electoral platforms are

\footnotetext{
1 Universidade de Aveiro/ GOVCOPP - Unidade de Investigação em Governança, Competitividade e Políticas Públicas/ Departamento de Ciências Sociais, Políticas e do Território/Aveiro/Portugal. ORCID: https://orcid.org/0000-0001-5789-2386. E-mail: joaopalhau@ua.pt

2 Universidade de Aveiro/ GOVCOPP - Unidade de Investigação em Governança, Competitividade e Políticas Públicas/ Departamento de Ciências Sociais, Políticas e do Território/Aveiro/Portugal. ORCID: https://orcid.org/0000-0002-7044-2723. E-mail: patriciasilva@ua.pt

3 Universidade de Aveiro/ GOVCOPP - Unidade de Investigação em Governança, Competitividade e Políticas Públicas/ Departamento de Ciências Sociais, Políticas e do Território/Aveiro/Portugal. ORCID: https://orcid.org/0000-0003-2341-6482. E-mail: ednafalorca@ua.pt
} 
highly impervious to the salience of populism, even when considering a radical right-wing populist party that won a seat in Parliament. A positive correlation between the salience of populism and the degree of ideological radicalism has been identified.

Keywords: Populism; Portugal; political parties; 2019 election; party manifestos.

\section{Introdução}

Nas últimas décadas, particularmente na Europa e na América do Norte, a ascensão eleitoral de forças políticas disruptivas abalou os sistemas políticos de diversos países. A eleição de Trump nos EUA ${ }^{4}$, o Brexit ${ }^{5}$ ou as Eleições Europeias de 2019 suscitaram e renovaram 0 interesse público e académico sobre o populismo.

0 caso português tem sido considerado como uma exceção no contexto europeu e mundial em relação ao recrudescimento do populismo, particularmente de direita. Esta tese dominante tem sido questionada desde as eleições legislativas de 2019, que permitiram aumentar o número de partidos com representação parlamentar e incluir, entre estes, um partido tendencialmente antissistema de direita radical populista.

Este artigo pretende contribuir para a (re)avaliação da tese da excecionalidade do caso português, considerando a saliência do populismo nos programas eleitorais dos partidos que obtiveram representação parlamentar em 2019. Para tal, pretende-se não apenas identificar, quantificar e caracterizar a presença de diferentes dimensões de populismo nos seus programas eleitorais, mas também compreender a interação entre estas dimensões e as posições partidárias a elas associadas.

Os resultados desta análise sugerem a permeabilidade do sistema partidário a um partido antissistema, com a representação parlamentar de um partido de direita radical cujo discurso político mobiliza dimensões centrais do populismo. Contudo, considerando os programas eleitorais, a saliência do populismo é bastante reduzida, embora seja mais pronunciada entre os partidos que se situam nos extremos do espectro partidário.

0 artigo estrutura-se em quatro secções. A secção que se segue analisa o conceito de populismo e discute as suas dimensões centrais. A terceira secção analisa 0 caso de Portugal e inicia-se com a discussão da tese da excecionalidade portuguesa no quadro do populismo europeu. Segue-se uma caraterização do sistema partidário português e termina com a apresentação dos resultados eleitorais das Legislativas de 2019. Os dados e métodos utilizados para analisar e medir o populismo nos programas eleitorais são descritos na secção quatro. A secção cinco apresenta e discute os resultados. 0 artigo termina com algumas notas conclusivas e pistas para a investigação futura.

\section{Populismo: Um conceito multifacetado e "essencialmente contestado"}

0 conceito de populismo é, na imortalizada expressão de W. B. Gallie, um "conceito essencialmente contestado" (Gallie, 1956). Com efeito, persiste uma dificuldade em consolidar um significado universal, o que tem

4 Donald Trump venceu as eleições Presidenciais em 2016, tornando-se 0 quadragésimo quinto Presidente dos EUA. 0 seu mandato iniciou-se oficialmente a 20 de janeiro de 2017 e terminou a 20 de janeiro de 2021.

50 Brexit designa o processo de saída do Reino Unido da União Europeia. Este iniciou-se com a convocação de um referendo sobre a permanência do Reino Unido na União Europeia a 23 de junho de 2016, tendo saído vitoriosa a opção "Saída" (Leave) com 17410742 dos votos contra 16141241 votos favoráveis à opção "Permanência" (Remain). 
alimentado um prolífico debate entre académicos e políticos. Historicamente, o termo tem sido utilizado para classificar ou descrever indivíduos, instituições e fenómenos políticos díspares (como movimentos políticos, partidos políticos, líderes políticos, ideologias; políticas económicas), situados em contextos históricos e geográficos distintos (como a Rússia czarista no século XIX ou América Latina no século XX) e com um caráter ideológico muito variado (da esquerda radical à direita radical) (Gidron \& Bonikowski, 2014; Mudde \& Kaltwasser, 2017, pp. 19, 35-36, 59-80; Eatwell \& Goodwin, 2019, pp. 63-67, 75), conferindo-Ihe, assim, uma elasticidade semântica, aparentemente, inesgotável.

Este problema conceptual agrava-se com a associação e (ab)uso frequente do termo enquanto sinónimo de demagogia (sobretudo em contexto europeu) ou fascismo, bem como com a sua utilização para designar erradamente fenómenos políticos conceptualmente bem delimitados (como, por exemplo, clientelismo) (Mudde \& Kaltwasser, 2017, p. 14; Eatwell \& Goodwin, 2019, pp. 59-60). 0 conceito é, ainda, frequentemente utilizado como forma de atacar e desqualificar as ideias de determinados adversários políticos. Efetivamente, trata-se de um "rótulo" que raramente é assumido pelos atores políticos (sejam eles partidos, líderes ou movimentos políticos), dada a conotação negativa que possui em certos contextos históricos (Deegan-Krause \& Haughton, 2009, p. 822; Mudde \& Kaltwasser, 2017, p. 14; Panizza, 2005, p. 1; Rooduijn, 2019, pp. 365-366; Gidron \& Bonikowski, 2014; Eatwell \& Goodwin, 2019).

Apesar de a literatura reconhecer diversas abordagens para o estudo do populismo, todas compartilham certos aspetos (Gidron \& Bonikowski, 2014, p. 17; Rooduijn, 2019) nomeadamente o facto de que o populismo, independentemente da abordagem conceptual de partida ou da configuração específica que apresenta, pressupõe uma relação antagónica entre um "povo virtuoso" e uma "elite corrupta", envolvendo "sempre uma crítica do establishmente uma adulação do povo comum" (Mudde \& Kaltwasser, 2017, p. 18; Canovan, 1981, p. 294; Rooduijn, 2019; Eatwell \& Goodwin, 2019, p. 85).

Nesta investigação, o populismo é analisado de acordo com a abordagem ideacional proposta por Cas Mudde, segundo a qual o populismo se define como "uma ideologia de baixa densidade que considera que a sociedade está, em última instância, dividida em dois campos homogéneos e antagónicos - "o povo puro" versus "a elite corrupta" - e que defende que a política deveria ser uma expressão da volonté générale (vontade geral) do povo" (Mudde, 2004, p. 543; Mudde \& Kaltwasser, 2017, p. 18). Esta abordagem assenta numa conceção de populismo não essencialista, na medida em tanto o "povo" como a "elite" são construções mentais, definidas discursivamente pelos agentes populistas através de um processo de determinação das fronteiras que separam os membros de cada uma das categorias, pelo que os elementos que as caraterizam não são fixos.

Um dos aspetos centrais da relação antagónica entre povo e elite relaciona-se com o facto de ela ser de natureza moral (não situacional), e, particularmente, maniqueísta (bem vs. mal). A elite, é vista como inimigo político, acusada de ignorar ou agir contra os interesses do povo (Mudde, 2004). Nesta definição mínima podemos identificar os três conceitos nucleares que constituem a morfologia interna da ideologia populista: Povo, Elites, Vontade Geral. Passamos agora a analisar em pormenor cada um deles e a forma como se relacionam.

0 caráter vago do termo "povo" leva Laclau $(2005$, p. 40) a afirmar que se trata de um significante vazio, isto é, um termo ao qual podem ser atribuídos uma multiplicidade de conteúdos e significados, possibilitando, consequentemente, a sua utilização em contextos diversos. 0 "povo", no âmbito do populismo, corporiza o conjunto dos indivíduos que foram despojados, negligenciados, ou excluídos da esfera pública (Panizza, 2005, p. 17) e 0 seu uso surge mais frequentemente associado a três principais significados: "povo como soberano", "povo como as pessoas comuns" e "povo como nação" (Mudde \& Kaltwasser, 2017, p. 22). 
0 uso de "povo" com o significado de soberano sublinha a ideia de que o povo é, em última instância, a fonte legítima do poder político e possui o direito de se insurgir contra o poder estabelecido, caso os seus os seus interesses não sejam devidamente acautelados. 0 uso de "povo" como pessoas comuns (Mudde \& Kaltwasser, 2017, p. 23) implica uma crítica da cultura dominante, afastada das "pessoas comuns" e desalinhada dos seus interesses, reivindicando, assim, a dignidade e o reconhecimento de grupos que, objetiva ou subjetivamente, estão a ser excluídos do poder devido ao seu estatuto sociocultural ou socioeconómico. Este significado é "simultaneamente integrador e divisor", na medida em que tanto fomenta a união do "povo" como aponta e denuncia um inimigo, frequentemente os partidos políticos, identificados como os responsáveis pelo descontentamento existente e como um obstáculo à mediação genuína entre os líderes populistas e as "pessoas comuns" (Mudde \& Kaltwasser, 2017, pp. 23-24). 0 uso de povo como nação designa a "comunidade nacional, definida em termos étnicos e cívicos", implicando a inclusão de todos os "nativos", que conjuntamente, formam uma comunidade com uma vida comum (Mudde \& Kaltwasser, 2017, p. 24).

À semelhança do "povo" também a categoria "elite" pode ser definida como um grupo social homogéneo, maioritariamente corrupto, acusado de ignorar ou desrespeitar a "vontade geral" e identificado pelos populistas como um inimigo a combater. É de salientar a autoexclusão ativa dos populistas e dos seus simpatizantes em relação à elite "corrupta" que condenam (Mudde \& Kaltwasser, 2017, p. 25).

A elite é definida com base no poder que possui e exerce numa dada esfera, quer seja política (ex: ocupação de um cargo político relevante), económica (ex: detentores dos meios de produção) ou cultural (domínio sobre os meios de comunicação ou produção intelectual). É geralmente identificada com base em critérios económicos (classe social) ou de nacionalidade (autenticidade). Na Europa Ocidental, as elites não são censuradas com base num critério étnico, uma vez que que, em geral, são da mesma etnia que os nativos. Neste contexto, a xenofobia populista (típica do populismo de direita) visa aqueles que são excluídos da construção étnica de "povo": os não-nativos, como os imigrantes, mas também minorias identificadas como uma ameaça em relação ao estatuto socioeconómico e/ou cultural do "povo" (ex: comunidade LGBT+ ou muçulmanos). As elites, neste caso, são acusadas de favorecer os interesses destes grupos sociais e de negligenciar os interesses do "povo" genuíno e maioritário (Mudde \& Kaltwasser, 2017, pp. 25-29).

A elite surge também associada ao poder económico, sendo esta associação transversal quer ao populismo de esquerda, quer ao populismo de direita. Comummente, os populistas de esquerda associam o populismo a uma forma vaga de socialismo, enquanto os populistas de direita denunciam a existência de uma ligação entre a elite política e a elite económica patente no favorecimento de interesses particulares em detrimento dos "interesses gerais" do povo (Mudde \& Kaltwasser, 2017, p. 26).

A União Europeia, por exemplo, é frequentemente utilizada pelos populistas como arma de arremesso contra as elites que, alegadamente, colocam os interesses da UE acima dos interesses nacionais.

0 princípio da "vontade geral" (Volonté Générale), entendido como a capacidade do povo se organizar e, conjuntamente, de exercer o poder político e materializar o interesse comum 6 inspira-se em Rousseau (1981, p. 81). Reflete, em grande medida, a visão populista de democracia. As democracias liberais modernas, apesar de assentarem no princípio da soberania popular, encontram-se também munidas de estruturas institucionais que impedem a "tirania da maioria" (Tocqueville, 2002, pp. 114-122) através da proteção dos direitos das minorias, nomeadamente através da sua consagração em constituições (escritas ou não). 
0 caráter liberal das democracias atuais reflete-se, por um lado, na importância atribuída aos direitos e à proteção dos indivíduos e, por outro, na sua natureza representativa, pela qual o poder dos cidadãos é delegado nos representantes por eles eleitos. A forma representativa da democracia liberal é um alvo primordial das críticas populistas. Em geral, os populistas consideram-na uma forma aristocrática de poder, na qual os cidadãos estão apartados da governação, limitando-se a ser a fonte do poder político, ou seja, a escolher os seus representantes mediante eleições periódicas, mas permanecendo distantes e destituídos de um verdadeiro poder de tomada de decisão sobre assuntos importantes (Canovan, 1999; Mudde \& Kaltwasser, 2017, pp. 30-31).

Todavia, o populismo não é contra o princípio da representação per se, não sendo, portanto, inerentemente contra 0 caráter representativo das democracias contemporâneas. A crítica populista, na verdade, é endereçada aos agentes dessa representação, às elites políticas (Mudde, 2004). A solução populista para este impasse passa por resgatar e revitalizar o ideal democrático da soberania popular através de instrumentos de democracia direta - referendos, plebiscitos, consultas populares, etc. Estes meios são apresentados como a possibilidade material de devolver ao povo o seu legítimo poder de tomada de decisão, que as instituições da democracia representativa têm paulatinamente corrompido e anulado.

De facto, a democracia liberal representativa assenta num compromisso complexo entre democracia popular e elitismo liberal, no qual os princípios de racionalidade tecnocrática e a tutela constrangem ou anulam a soberania popular (sendo, por isso, apenas parcialmente democrática) (Mudde, 2004; Panizza, 2005, p. 31), havendo sempre um fosso entre o ideal abstrato da democracia e a sua prática (Schmitter \& Karl, 1991). A política populista procura explorar esta tensão inerente à lógica de funcionamento das democracias modernas, politizando as fragilidades que ela pode acarretar e instrumentalizando-as como forma de ataque.

0 populismo surge, assim, como uma reação (sendo visto como causa e consequência) face às incapacidades/limitações das democracias em responder eficazmente aos problemas e necessidades dos cidadãos, afirmando-se como uma alternativa ao status quo e uma exigência de aprofundamento de alguns dos valores democráticos, nomeadamente, do princípio da soberania popular (Panizza, 2005; Mouffe, 2002; Mudde, 2004; Mudde \& Kaltwasser, 2017, p. 102).

\section{Populismo, Sistemas Partidários e Partidos Políticos}

Uma das instituições da democracia representativa frequentemente condenada pelos populistas são os partidos políticos. Os partidos são centrais nas democracias modernas, desempenhando um papel fundamental no processo de representação política (agregação de preferências coletivas; elaboração de programas políticos; preparação de representantes políticos). Nas democracias modernas, os cidadãos delegam o seu poder político num conjunto de representantes que agem e decidem em seu nome, constituindo uma elite política mais ou menos profissionalizada.

Por esta razão, as elites políticas são associadas aos partidos políticos existentes, particularmente, os que possuem representação parlamentar e capacidade para influenciar o processo de tomada de decisão. Os agentes populistas acusam os partidos políticos de serem organizações corruptas, que servem interesses próprios e não representam genuinamente os interesses e necessidades do povo. 0 que pretendem é desafiar o poder estabelecido e fazer eleger os seus representantes, apresentando-se como os porta-vozes genuínos do povo. Assim, os partidos políticos constituem uma das principais formas de mobilização populista (Mudde \& Kaltwasser, 2017, p. 69). 
No contexto europeu, o populismo tem sido sobretudo associado a partidos de direita radical (Mudde, 2004; Mouffe, 2002), embora na sequência da crise da zona euro se tenha destacado a emergência de partidos populistas de esquerda radical (Lisi \& Borghetto, 2018; Ramiro \& Gomez, 2017; Stavrakakis \& Katsambekis, 2014). Existe ainda uma considerável variação quanto à estabilidade dos partidos populistas. Existem casos de partidos populistas relâmpago ${ }^{7}$, como o Movimento Popular pela Letónia (TKL), ou partidos bem estabelecidos que se institucionalizaram e consolidaram numa forte organização partidária, como a União Nacional em França (Mudde \& Kaltwasser, 2017, pp. 70-71).

Os partidos populistas caraterizam-se também por procurarem ativamente construir um modelo de partido que thes permita demarcarem-se dos partidos estabelecidos. Isto tem-se traduzido em caraterísticas como uma retórica pautada pela defesa de uma interação e participação direta dos membros dos partidos. Distinguem-se também pelas suas lideranças personalistas (Taggart, 2000, pp. 72-76).

A literatura tem sublinhado a existência de relações entre a adesão ao populismo e variáveis como a idade do partido, a sua posição no sistema partidário, a sua participação no governo bem como o grau de radicalismo ideológico.

Num estudo com enfoque no caso da Eslováquia concluiu-se que os partidos mais novos, com fraca institucionalização e menos participação no governo, tendem a aderir mais facilmente ao populismo do que partidos mais solidamente institucionalizados no sistema partidário (Deegan-Krause \& Haughton, 2009).

Por outro lado, os partidos challenger (que desafiam o status quo) tendem a aderir mais ao populismo do que os partidos mainstream ("arco da governação"), embora se verifiquem alguns casos de spill-over populista a atores políticos do establishment que, para combater os populistas, aderem à sua retórica e politizam os seus temas predominantes (Mudde, 2004; Van Spanje, 2010). Diversos trabalhos têm reconhecido que, enquanto ideologia, o populismo pode ser perfilhado por partidos de esquerda (March, 2007; Stavrakakis \& Katsambekis, 2014) ou de direita (Mouffe, 2002; Mudde, 2007; Bobba \& McDonnell, 2016), apresentando configurações que combinam elementos de diferentes ideologias: neoliberalismo, conservadorismo, nacionalismo, nativismo, autoritarismo ou socialismo (Weyland, 2003; Martin, 2012, pp. 71129; Charaudeau, 2016; Martinelli, 2018; Moreau, 2018; Bonikowski, 2017; Bonikowski, Halikiopoulou, Kaufmann, \& Rooduijn, 2019; Loew \& Faas, 2019).

A literatura tem também sublinhado a existência de uma correlação positiva entre a adesão ao populismo e 0 grau de radicalismo ideológico dos partidos, verificando-se que os partidos mais radicais, de direita ou esquerda, tendem a ser mais permeáveis ao populismo do que os partidos ideologicamente moderados (Rooduijn \& Akkerman, 2017; Meijers \& Zaslove, 2021). Além disso, alguns autores têm classificado os diferentes tipos de populismo com base no seu grau de inclusão/ exclusão associando-0 ao posicionamento ideológico dos atores políticos. 0 populismo de esquerda é tendencialmente mais inclusivo, ao passo que o populismo de direita é tendencialmente mais excludente (Mudde \& Kaltwasser, 2012; Mouffe, 2018, p. 34; Cleen, 2018). Chantal Mouffe defende que a distinção entre populismo de esquerda e direita radica na forma como é estabelecida a fronteira política que separa "o povo" da "elite" e, principalmente, na constituição do "povo". De facto, quem constitui o "povo" é a chave para decifrar o grau de inclusão e exclusão de um dado subtipo de populismo e, por conseguinte, de o categorizar como sendo de direita ou de esquerda. 0 "povo"

7 Tradução de "flash parties", expressão utilizada para designar os partidos políticos que, embora alcancem proeminência no sistema partidário pontual, não chegam a institucionalizar-se, acabando por desaparecer (Rose \& Mackie, 1988). 
do populismo de direita exclui um conjunto de grupos sociais, nomeadamente imigrantes (enquadrados pelos populistas como uma ameaça para o estatuto socioeconómico e sociocultural dos nativos), enquanto o populismo de esquerda, segundo a autora, deve procurar construir um "povo" inclusivo, numa lógica de uma "cadeia de equivalências", "entre as exigências dos trabalhadores, dos imigrantes e da classe média em situação precária, bem como algumas exigências democráticas de outra natureza, como as da comunidade LGBT" (Mouffe, 2018, p. 34) ${ }^{8}$.

\section{Portugal e Populismo}

Até às legislativas de 2019, a investigação existente destacava essencialmente dois temas e ideias intimamente interrelacionadas: i) a ausência de populismo em Portugal; ii) a relação entre a crise da zona euro e a ausência (geral) de populismo (Salgado, 2019; Quintas da Silva, 2018; Carreira da Silva \& Salgado, 2018; Lisi \& Borghetto, 2018; Lisi, Llamazares, \& Tsakatika, 2019).

Até 2019, Portugal era, em larga medida, considerado um caso excecional relativamente à tendência de crescimento do populismo que se verifica no espaço europeu e mundial. Esta excecionalidade tem sido explicada com base num conjunto de fatores ligados à especificidade histórica e contextual de Portugal. Entre eles destacam-se a rejeição de ideias, partidos e movimentos de extrema direita devido ao "peso" da ditadura do Estado Novo na memória coletiva; a agregação do descontentamento popular por partidos de esquerda como 0 Partido Comunista Português (PCP) e o Bloco de Esquerda (BE), nomeadamente através do controlo dos sindicatos pelo PCP, que tem tido um papel importante em travar o desenvolvimento de outro tipo de enraizamento de movimentos fortes e independentes, não ligados a partidos políticos existentes (Salgado, 2019); a expressão residual da imigração enquanto tema preocupante; as atitudes claramente mais europeístas dos portugueses, mesmo no contexto da crise e tratando-se de um assunto pouco mobilizado pelos partidos políticos ${ }^{9}$; o facto de a dimensão socioeconómica constituir a principal preocupação dos portugueses, deixando pouco espaço para a agenda identitária e nacionalista típica do populismo de direita; e, por último, a falta de habilidade da extrema direita portuguesa (até aqui o Partido Nacional Renovador - PNR) em tirar partido das redes sociais e mobilizar apoio social e eleitoral (Quintas da Silva, 2018).

0 contexto da crise da zona euro permitiu destacar esta excecionalidade, face aos congéneres da Sul da Europa. À semelhança de países como Espanha e Grécia, também Portugal foi profundamente afetado pela crise da zona euro (2010-2013), tendo sido alvo de um resgate financeiro e de um conjunto de medidas de austeridade impostas pela Troika $^{10}$, que se caraterizaram por uma redução das despesas com o Estado Social (Ex: cortes em salários e pensões; aumento de impostos; redução de direitos sociais; privatizações) (Abreu et al., 2013; Pinto \& Teixeira, 2019). No entanto, em comparação com estes países, e apesar de fatores como o profundo descontentamento popular, a elevada taxa de desemprego e o aumento do euroceticismo, 0 aumento do populismo em Portugal não foi significativo. Pelo contrário, o caso português destacou-se pela sua resiliência, patente em aspetos como a manutenção de um sistema partidário relativamente fechado, sem a entrada para o Parlamento de partidos populistas com uma retórica anti-establishment (Lisi \& Borghetto, 2018; Lisi et al., 2019; Giorgi \& 
Santana-Pereira, 2021); 0 insucesso eleitoral de partidos de direita radical; a ausência de novos partidos de protesto com vista a canalizar o descontentamento popular; e a reduzida permeabilidade dos meios de comunicação social ao populismo (Salgado, 2019).

Apesar desta tendência geral, identificam-se algumas nuances que merecem a nossa atenção. Embora as repercussões políticas da crise da zona euro tenham sido menos impactantes do que em Espanha ou na Grécia, em Portugal, no rescaldo da crise, é entre os partidos mais à esquerda, PCP e BE, que se verifica um aumento da adesão à retórica populista, quer nos programas eleitorais (Lisi \& Borghetto, 2018), quer nos discursos públicos (discursos de líderes e debates parlamentares), nos quais a Troika foi, por vezes, enquadrada numa relação antagónica de tipo "nós" versus "eles" e apresentada como uma espécie de invasor que impôs ao povo português trabalhador uma injusta punição (Carreira da Silva \& Salgado, 2018).

Quanto ao subtipo de populismo, apesar de se encontrarem exemplos de populismo excludente no Sul da Europa (Lisi \& Borghetto, 2018), o populismo ibérico é principalmente de natureza inclusiva, visto que mesmo os partidos com posições eurocéticas, como é o caso do PCP e do BE em Portugal, têm posições favoráveis em relação às leis de imigração e orientações multiculturais. Outra característica importante que distingue o populismo ibérico é que este apresenta uma dimensão socioeconómica (com foco nos mais pobres e prejudicados pela crise e pela austeridade) em contraste com o populismo de direita radical predominante na Europa, mais focado em questões de identidade e de nacionalidade (Cachafeiro \& Plaza-Colodoro, 2018).

A impermeabilidade do sistema partidário português em relação ao populismo tem sido questionada desde as eleições legislativas de 2019 (Valle, 2021; Marchi, 2020). Estas eleições registaram um número recorde de candidaturas, com 21 partidos políticos a concorrer. Destes, apenas dez partidos conseguiram representação parlamentar. 0 Partido Socialista (PS) sagra-se vencedor das eleições com uma maioria relativa (36,33\% dos votos), seguido do Partido Social-Democrata (PSD), com $27,8 \%$ dos votos, ficando o BE em terceiro lugar (9,5\% dos votos). 0 quarto lugar é ocupado pelo PCP-PEV (6,3\%), seguido do Partido Popular (CDS-PP) com 4,2\% dos votos e do Partido Pessoas-Animais-Natureza (PAN) com 3,3\% dos votos (Gráfico n. ${ }^{0}$ 1).

Estas eleições destacam-se pela entrada de três novos partidos para a Assembleia da República: o Livre (L) (1,09\% dos votos); o Chega (CH) (1,29\% dos votos) e a Iniciativa Liberal (IL) (1,29\% dos votos) - tendo cada um deles obtido um assento parlamentar. Ideologicamente, o Livre tem sido considerado um partido de esquerda libertária e europeísta (Jalali, Moniz, \& Silva, 2020). 0 CH e a IL situam-se, pelo contrário, à direita do espectro político. $0 \mathrm{CH}$ tem-se posicionado como um partido antissistema e tem sido considerado pelos especialistas como um partido de direita radical populista (Marchi, 2020, pp. 191-201), enquadrando-se na tipificação definida por Cas Mudde (Mudde, 2007, pp. 12-31). Quanto à IL, o partido define como sua missão "promover e defender 0 Liberalismo em Portugal"11, consistente com a sua posição como partido liberal a nível social e económico (Jalali et al., 2020).

As Legislativas de 2019 constituem um caso de estudo relevante sobre populismo nos partidos políticos portugueses. Com a entrada de três novos partidos para o Parlamento e, nomeadamente de um partido antissistema, importa não só dar continuidade e atualizar o conhecimento sobre populismo nos partidos portugueses considerando este ato eleitoral, mas também perceber até que ponto os novos partidos introduzem alterações em termos da representação programática com assento parlamentar e em que medida são permeáveis ao populismo nos seus programas eleitorais. 


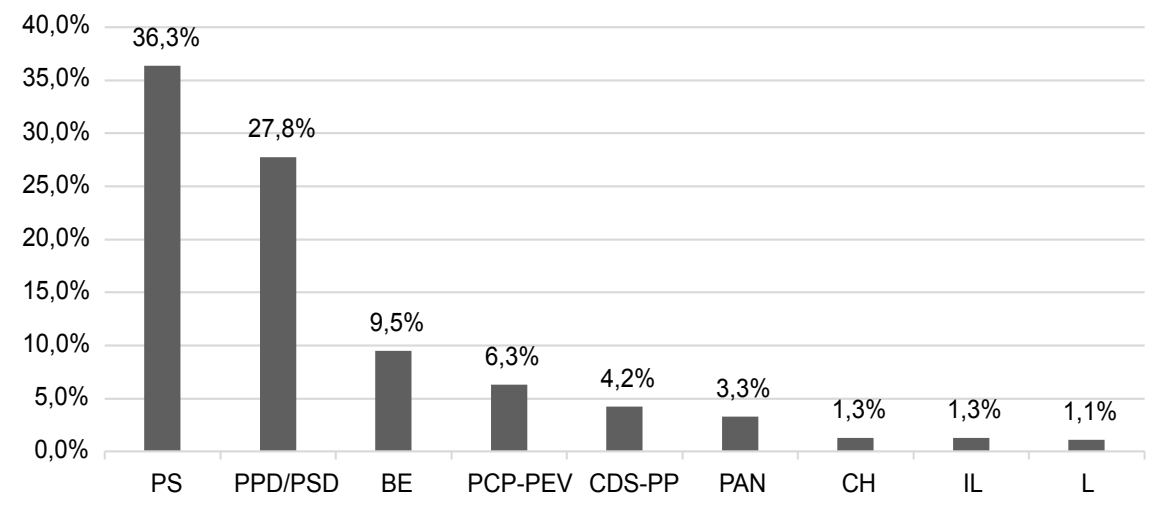

\section{Gráfico n. ${ }^{0} 1$ - Distribuição percentual dos votos obtidos pelos partidos nas Legislativas de $\mathbf{2 0 1 9}$}

Fonte: Ministério da Administração Interna. Retirado de https://www.eleicoes.mai.gov.pt/legislativas2019/.

\section{Dados e métodos}

Este artigo pretende analisar a saliência do discurso populista nos programas eleitorais dos partidos políticos portugueses, nas eleições legislativas de 2019. Para este efeito, dois objetivos operacionais interrelacionados foram considerados. Primeiro, pretende-se identificar, quantificar e caracterizar a presença de dimensões centrais de populismo nos conteúdos programáticos e, em segundo lugar, compreender e caracterizar a relação entre a saliência destes traços de populismo e as áreas temáticas nas quais eles se encontram inseridos.

Em termos empíricos, foram analisados os programas eleitorais dos partidos que obtiveram representação parlamentar em 2019. Os programas eleitorais são fontes reconhecidamente assertivas, objetivas e ricas para a identificação do posicionamento ideológico e da vontade coletiva dos partidos (Fagerholm, 2016; Ferreira, 2016, p. 93). Além disso, as posições programáticas e as ideologias adotadas pelos partidos têm sido identificadas como uma dimensão fundamental para explicar a estrutura e as mudanças que ocorrem no sistema partidário, tendo em consideração o papel central que desempenham na definição dos padrões de interação partidária cooperação e competição (Bosco \& Morlino, 2006; Lisi, 2011, p. 35).

A estratégia metodológica replica a abordagem de análise dos programas eleitorais estabelecida pelo Manifesto Research on Political Representation (MARPOR). 0 MARPOR afirma-se como um instrumento privilegiado para análises comparativas e longitudinais, sendo considerado uma das fontes mais sistemáticas e objetivas na avaliação do posicionamento programático e ideológico dos partidos políticos. Tal permite conhecer o posicionamento programático (e, sobretudo, a saliência temática ${ }^{12}$ ) e ideológico (esquerda-direita) dos partidos, e compreender até que ponto o posicionamento dos novos partidos - Livre (L); Chega (CH) e Iniciativa Liberal (IL) - expõe uma continuidade ou uma alteração na representação programática e ideológica existente entre os partidos com assento parlamentar.

12 Esta abordagem assenta a sua análise nos pressupostos da teoria da saliência da competição partidária. Segundo esta é possível determinar as posições partidárias em função da frequência com que determinados temas surgem nos programas eleitorais. 0 argumento principal sustenta que os partidos conferem maior saliência aos assuntos que têm maior relevância para si e em relação aos quais têm maior capacidade de mobilização (Gabel \& Huber, 2000; Krouwel \& Van Elfrinkhof, 2014). 
Apesar das suas virtudes, o esquema de categorias do MARPOR tem capacidade limitada para enquadrar adequadamente certas questões políticas, como o populismo. Por esta razão, a análise e operacionalização de populismo, embora seja feita com base nas instruções de codificação abordagem do MARPOR - nomeadamente a ponderação de quasi-sentences ${ }^{13}$ como unidade de análise - segue um esquema de análise distinto, conforme se apresenta no Quadro n. ${ }^{0}$ 1. Esta operacionalização baseia-se na desagregação do conceito em três dimensões centrais - Povo Virtuoso, Anti-Elitismo e Soberania Popular. Os critérios que presidiram a esta opção metodológica refletem as vantagens que ela acarreta para os nossos propósitos de investigação, nomeadamente a possibilidade de uma análise mais "fina" que permita identificar, distinguir e caracterizar as diferentes dimensões que compõem o núcleo do discurso populista e, assim, identificar e caracterizar diferentes padrões de saliência entre os partidos políticos portugueses. Além disto, a análise discriminada de cada dimensão permite identificar eficazmente as áreas temáticas e posições partidárias às quais o populismo mais frequentemente se associa.

\section{Quadro n. ${ }^{0} 1$ - Operacionalização das dimensões de populismo}

\begin{tabular}{|c|c|c|}
\hline $\begin{array}{l}\text { Dimensões } \\
\text { centrais }\end{array}$ & Definição & Exemplos \\
\hline $\begin{array}{l}\text { Povo } \\
\text { Virtuoso }\end{array}$ & $\begin{array}{l}\text { Entidade coletiva, homogénea } \\
\text { e virtuosa que ocupa uma } \\
\text { posição social desvantajosa }\end{array}$ & $\begin{array}{l}\text { "Nós", "Todos", "Povo"; "os Portugueses"; } \\
\text { "os contribuintes"; "os cidadãos"; "o país" }\end{array}$ \\
\hline Anti-Elitismo & $\begin{array}{l}\text { Entidade coletiva, homogénea } \\
\text { e corrupta, que ocupa uma posição } \\
\text { social vantajosa assente numa } \\
\text { determinada forma de "poder" }\end{array}$ & $\begin{array}{l}\text { "a classe política"; "os banqueiros"; "os políticos"; } \\
\text { "a elite"; "os intelectuais"; "as corporações", } \\
\text { "0 sistema"; "os partidos do sistema"; } \\
\text { "os interesses instalados". }\end{array}$ \\
\hline $\begin{array}{l}\text { Soberania } \\
\text { Popular }\end{array}$ & $\begin{array}{l}0 \text { povo é a fonte legítima } \\
\text { de poder político e deve ser } \\
\text { o verdadeiro governante }\end{array}$ & $\begin{array}{l}\text { "o povo deve governar", "o povo é soberano", } \\
\text { "o povo é quem mais ordena", "governo do povo", } \\
\text { "soberania popular", "plebiscito", "iniciativa } \\
\text { popular", "consulta popular", "petição", "referendo" }\end{array}$ \\
\hline
\end{tabular}

Fonte: Adaptado da abordagem ideacional de populismo (Mudde \& Kaltwasser, 2012; Hawkins et al., 2019; March, 2017; Manucci \& Weber, 2017).

Para a codificação do conteúdo populista foi considerado não só o conteúdo explícito (expresso objetivamente pelas palavras utilizadas), mas também o conteúdo implícito (sujeito à interpretação dos significados considerando o contexto em análise). Um aspeto que distingue esta operacionalização em relação aos estudos sobre populismo em Portugal relaciona-se com a utilização da quasi-sentence como unidade de análise, ao invés de parágrafos (Lisi \& Borgettho, 2018; Valle, 2021) ou da totalidade do programa eleitoral (Lisi et al., 2019). 
Com efeito, diversos estudos qualitativos sobre populismo privilegiam segmentos de texto longos - frases ou parágrafos - como unidade de análise, ao invés de palavras (Manucci \& Weber, 2017; Lisi \& Borghetto, 2018; Rooduijn \& Pauwels, 2011), uma vez que a expressão verbal de ideias populistas, por vezes, tende a manifestar-se textualmente de forma mais difusa e latente. Além disso, o seu entendimento pressupõe um conhecimento do contexto sociopolítico onde os conteúdos se inserem (Hawkins et al., 2019, p. 3).

Por outro lado, o uso da quasi-sentence é uma conveniência necessária, tendo em consideração a articulação entre os objetivos operacionais deste estudo, nomeadamente, o cruzamento de dados entre a codificação com base no esquema de categorias do MARPOR e a codificação com base no esquema de categorias tripartido de populismo, visto que a comparação entre os dados resultantes das duas codificações implica a manutenção da mesma unidade de análise. Importa sublinhar que, consideradas individualmente, as unidades de análise não correspondem a populismo per se, mas apenas a uma das três dimensões do conceito de populismo, tal como 0 operacionalizamos.

Em termos dos dados, foram considerados os conteúdos dos programas eleitorais dos partidos políticos que obtiveram representação parlamentar em virtude dos resultados das eleições legislativas de 2019. Assim, são alvo de análise os programas eleitorais dos seguintes dez partidos: Partido Comunista Português, Partido Ecologista 'Os Verdes' (PEV), Partido Socialista, Partido Social-Democrata, Partido Popular, Bloco de Esquerda, Iniciativa Liberal, Partido Pessoas, Animais e Natureza, Chega e Livre.

\section{Análise e discussão dos resultados}

Este artigo pretende analisar a saliência das três dimensões centrais de populismo nos conteúdos programáticos e compreender como estas se articulam com as áreas políticas centrais defendidas nos programas eleitorais.

\section{a) 0 posicionamento dos partidos em 2019}

De acordo com a operacionalização do RILE14, os programas eleitorais de sete partidos, em 2019, apresentaram-se à esquerda (BE, PCP, PEV, PAN, L, PS e PSD) e três partidos à direita (CH, IL e CDS-PP). 0 PSD surge no continuum como o partido mais próximo do centro, tal como se pode verificar no Gráfico n. ${ }^{0} 2$. Sendo certo que os partidos mudam e as suas preferências programáticas podem alterar-se em função do contexto, é facilmente compreensível a aproximação do PSD ao centro-esquerda. É, contudo, um efeito contextual, dado que o PSD tem sido consistentemente posicionado à direita por eleitores e peritos (Bakker et al., 2020). 

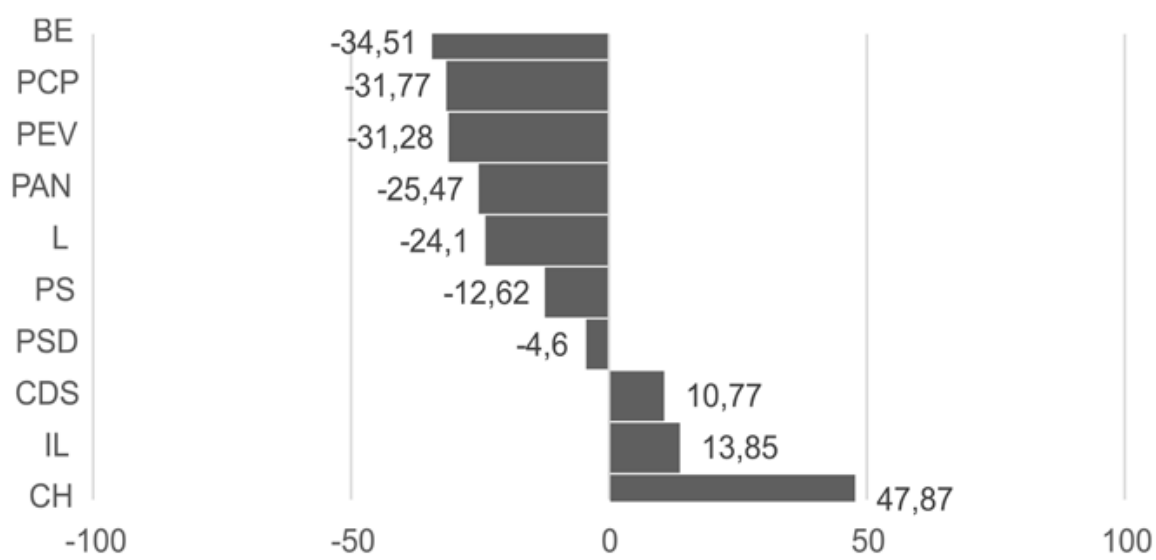

\section{Gráfico n. ${ }^{0} 2$ - Posicionamento dos Partidos Políticos (2019)}

\section{b) Populismo e as suas dimensões}

Quanto aos novos partidos - CH, L e IL -, os posicionamentos do RILE (right-left scale) estão em consonância com a classificação atribuída pelos estudos mais recentes (Jalali et al., 2020; Marchi, 2020). Assim, neste estudo, os partidos de esquerda são o L, o PCP, o BE, o PS, o PEV, o PAN e os partidos de direita são o PSD, 0 CDS-PP, o CH e o IL.

Considerando a análise dos dez programas eleitorais, concluímos que nove apresentam alguma dimensão de populismo - CH, PCP, L, BE, PSD, PAN, PS, IL, CDS-PP (ver gráfico n. ${ }^{\circ} 4$ ). 0 programa do PEV destaca-se por ser 0 único onde não se identificaram quaisquer dimensões de populismo. Considerando todos os partidos, foram codificadas um total de 16634 quasi-sentences. Destas, apenas 186 apresentam alguma dimensão de populismo, ou seja, cerca de 1,1\% do total. Conclui-se, por isso, que a saliência de dimensões de populismo nos programas eleitorais de 2019 é bastante reduzida.

Quanto às dimensões analisadas, observam-se diferentes graus de saliência, sendo que, globalmente, 0 Anti-Elitismo é a dimensão mais proeminente (64\%), seguindo-se a Soberania Popular (21\%) e, em último, 0 Povo Virtuoso (15\%), confirme se pode verificar no Gráfico n. 3. 


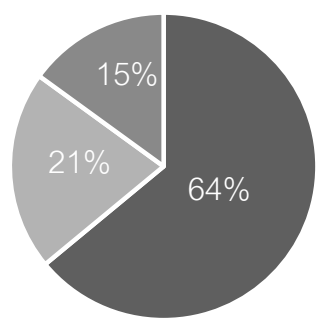

- Anti-Elitismo = Soberania Popular - Povo Virtuoso

\section{Gráfico n. ${ }^{0} 3$ - Saliência das dimensões de populismo nos programas eleitorais}

Considerando cada partido, observa-se uma distribuição desigual quanto à saliência de dimensões de populismo nos seus programas eleitorais, com destaque para o $\mathrm{CH}(5,5 \%)$ e o $\mathrm{PCP}(5,5 \%)$ que apresentam maior saliência de populismo. Em sentido contrário, o CDS-PP (0,04\%) e a IL (0,1\%) distinguem-se como os partidos com menor saliência de populismo (Gráfico n. ${ }^{\circ}$ 4).

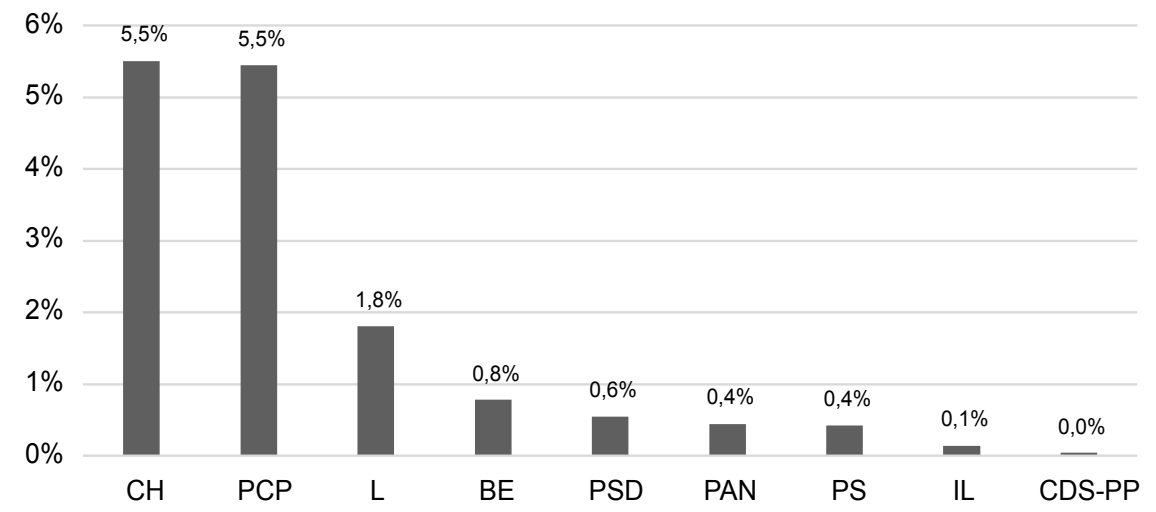

Gráfico n. $^{0} 4$ - Saliência do populismo por programa eleitoral (\% do total de quasi-sentences)

A análise de populismo com base na operacionalização das suas três principais dimensões - Soberania Popular, Anti-Elitismo e Povo Virtuoso - permitiu evidenciar um conjunto de nuances importantes e, assim, distinguir os partidos não só em termos do número de dimensões encontradas, mas também relativamente ao seu grau de saliência, como se apresenta no Gráfico n. ${ }^{0} 5$. Considerando o panorama geral, apenas quatro partidos mobilizaram, em alguma medida, as três dimensões de populismo - o CH, o PCP, o L e o BE. 0 PSD, por outro lado, apresenta conteúdos que se inserem apenas nas dimensões Anti-Elitismo e Povo Virtuoso. 


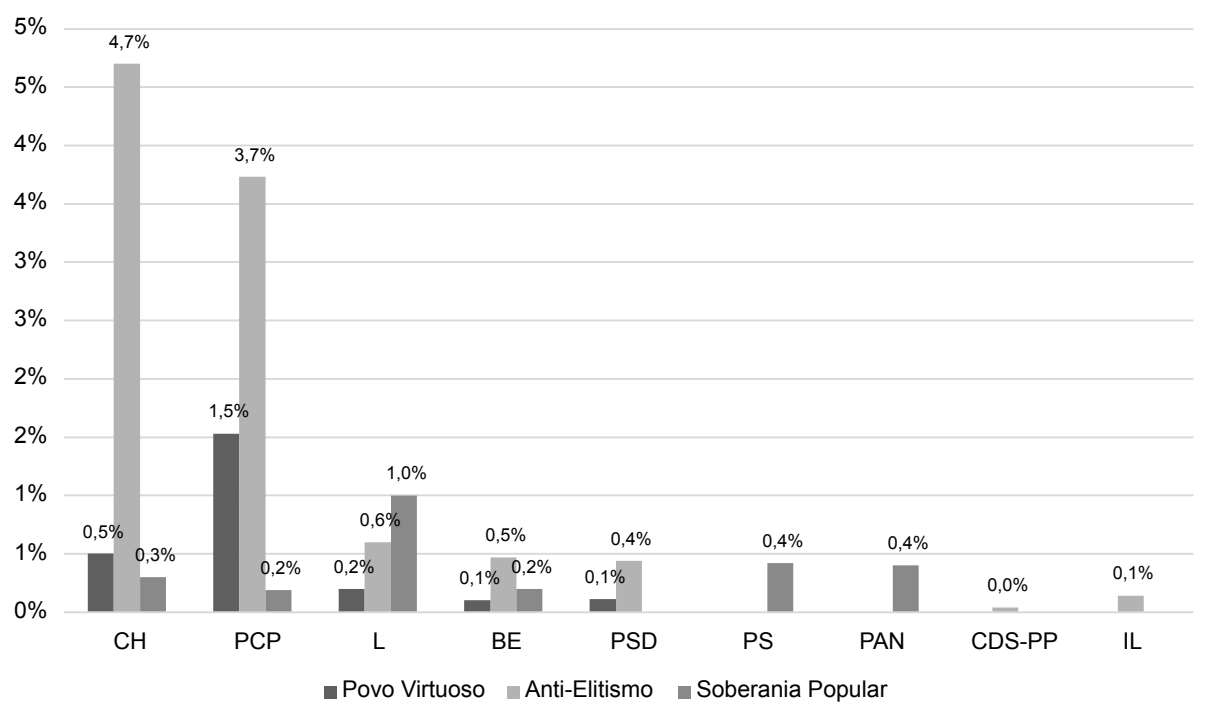

\section{Gráfico n. $^{0} 5$ - Saliência das dimensões de populismo (\%)}

0 CH destaca-se como o partido em que a saliência de apelos antielitistas é mais elevada (4,7\% do seu programa), nomeadamente quando condena a perpetuação das elites políticas no poder, ao contrapor os "direitos dos que chegaram primeiro contra os direitos dos que, legitimamente, querem ter a sua oportunidade de entrar. Direitos da pior das elites: a elite dos meramente instalados, que se define apenas porque já se lá está" (CHEGA, 2019, p. 15). Também no PCP esta é a dimensão mais saliente (3,7\% do seu programa). Tome-se, como exemplo, a ideia de que "não há solução para os problemas estruturais do País, com Orçamentos do Estado subordinados às imposições de Bruxelas e à lógica do capital monopolista, como ficou provado na legislatura que agora termina" (PCP, 2019, p. 25).

A União Europeia - organização que personifica a elite política europeia - é, em última instância, responsabilizada pela incapacidade de o País resolver os seus principais problemas, com o PCP a estimar que a sua atuação limita a autonomia e o poder de decisão política de Portugal. 0 PCP distingue-se, ainda, por ser o partido em que a dimensão Povo Virtuoso surge com maior frequência. Note-se, a título de exemplo, o tratamento do povo como uma entidade monolítica e a defesa das suas virtudes: "O Programa Eleitoral que o PCP apresenta, visa uma profunda transformação da realidade nacional, removendo os constrangimentos a que está sujeita, libertando as imensas potencialidades de desenvolvimento de que o País e o Povo português são portadores" (PCP, 2019, p. 15).

0 Livre destaca-se por ser o partido onde a Soberania Popular é mais saliente, visível em declarações como "Defendemos que os cidadãos devem controlar o futuro das suas comunidades" ou propostas concretas como "criando mecanismos de democracia deliberativa" e "criando Assembleias Cidadãs, compostas por participantes escolhidos de forma aleatória e de modo a garantir a maior representatividade possível (...)" (LIVRE, 2019, pp. 45-46). Quanto aos restantes partidos, identificou-se apenas uma das dimensões: Soberania Popular nos programas do PS e do PAN e Anti-Elitismo nos programas do CDS-PP e IL, sendo que em todos os casos os valores são muito residuais. 
Considerando o posicionamento no continuum esquerda-direita, verificamos que os partidos de esquerda são os que fazem mais apelos populistas (8,9\%), numa diferença de 2,7 pontos percentuais em relação aos partidos de direita (6,2\%). Em consonância com a investigação mais recente (Lisi \& Borgettho, 2018; Valle, 2021), estes resultados refletem a existência de uma correlação entre a ideologia, o grau de radicalismo e a posição no sistema partidário dos partidos e a sua adesão ao populismo. Os partidos mais radicais, quer à direita (CH), quer à esquerda (PCP, L e BE) são os que apresentam mais dimensões de populismo.

\section{Quadro $n .^{0} 2$ - Saliência de populismo nos partidos challenger e mainstream}

\begin{tabular}{|c|c|c|c|}
\hline Partidos Challenger & $\%$ & Partidos Mainstream & $\%$ \\
\hline CH & $5,5 \%$ & PSD & $0,6 \%$ \\
\hline PCP & $5,5 \%$ & PS & $0,4 \%$ \\
\hline L & $1,8 \%$ & CDS-PP & $0,04 \%$ \\
\hline BE & $0,8 \%$ & & \\
\hline PAN & $0,4 \%$ & & \\
\hline IL & $0,1 \%$ & Total & $0,3 \%$ \\
\hline Total & $14,1 \%$ & & \\
\hline
\end{tabular}

Comparativamente, a soma de populismo nos partidos challenger $(14,1 \%)-C H, L, I L, P A N, B E, P C P$ - é consideravelmente superior ao registado nos partidos mainstream (1\%) - PS, PSD, CDS-PP. Contudo, entre os challengers, a IL e o PAN surgem como exceções. A IL é o único challenger cuja saliência de dimensões de populismo é inferior aos dois principais partidos mainstream - PSD e PS. Por sua vez, o PAN encontra-se virtualmente "empatado" com o PS. Nos partidos mainstream, o populismo é inexpressivo, sendo praticamente inexistente no caso do CDS-PP.

De igual forma, não parece existir uma relação entre a (in)experiência parlamentar e a saliência do populismo. Com efeito, a diferença entre o total de populismo nos partidos com representação parlamentar antes das Legislativas $(7,7 \%)$ e nos partidos com representação recente $(7,5 \%)$ é residual. 
Quadro n. ${ }^{0} 3$ - Saliência de populismo nos partidos com representação parlamentar antes e depois das Legislativas de 2019

\begin{tabular}{|c|c|c|c|}
\hline $\begin{array}{c}\text { Partidos com } \\
\text { Representação Parlamentar } \\
\text { pré-Legislativas 2019 }\end{array}$ & $\%$ & $\begin{array}{c}\text { Partidos com } \\
\text { Representação Parlamentar } \\
\text { pós-Legislativas 2019 }\end{array}$ & $\%$ \\
\hline PSD & $0,6 \%$ & L & $1,8 \%$ \\
\hline PS & $0,4 \%$ & CH & $0,1 \%$ \\
\hline CDS-PP & $0,0 \%$ & & $5,5 \%$ \\
\hline BE & $0,8 \%$ & & \\
\hline PAN & $0,4 \%$ & & $7,5 \%$ \\
\hline PCP & $5,5 \%$ & Total & \\
\hline Total & $7,7 \%$ & & \\
\hline
\end{tabular}

\section{c) Populismo e áreas temáticas}

Interessa ainda compreender a relação que se estabelece entre populismo e as áreas temáticas em relação às quais este surge mais associado. Esta análise assenta no cruzamento de dados entre a codificação do MARPOR e a análise de populismo. 0 Gráfico n. ${ }^{\circ} 6$ ilustra as temáticas mais frequentemente associadas a quasi-sentences com dimensões de populismo, considerando todos os partidos alvo de análise.

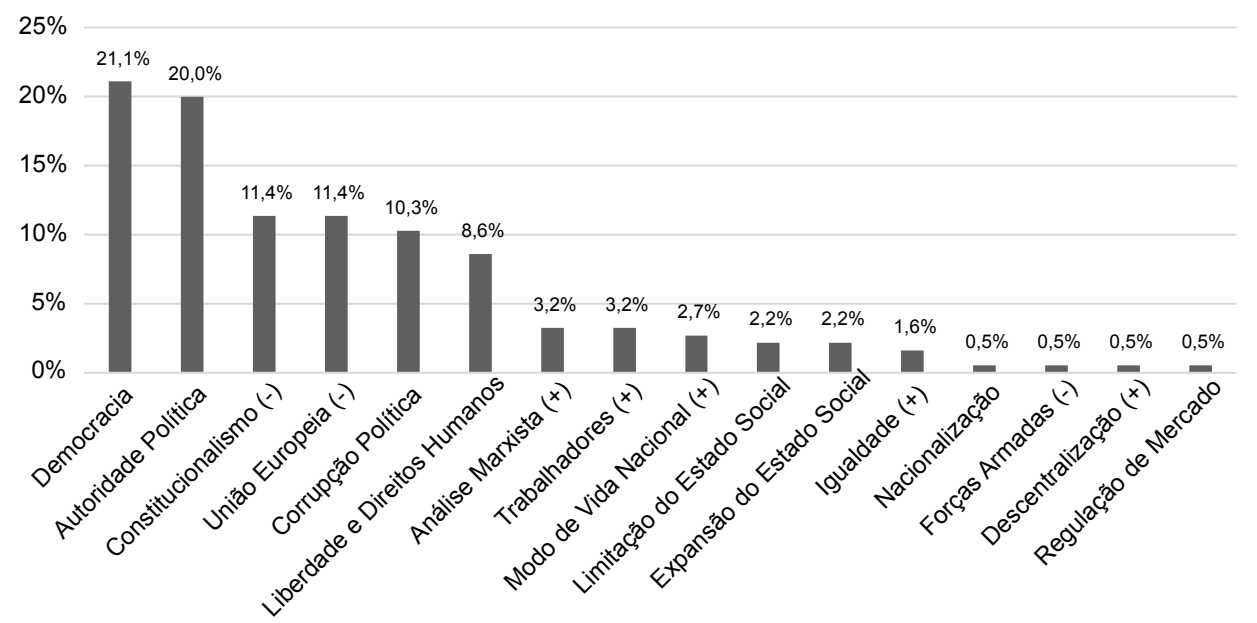

Gráfico n. ${ }^{0} 6$ - Áreas temáticas associadas às dimensões de populismo na globalidade dos partidos (\%) 
As 186 quasi-sentences identificadas com alguma dimensão de populismo surgem associadas a uma das dezasseis áreas temáticas expostas acima. Entre as mais salientes destacam-se: a temática Democracia (cerca de 21,1\%), Autoridade Política (cerca de 20,0\%), o Constitucionalismo (-) (cerca de 11,4\%) e a União Europeia (-) (cerca de 11,4\%) e Corrupção Política (cerca de 10,3\%).

Importa frisar que os valores das áreas temáticas Democracia, bem como Autoridade Política são o produto da agregação dos pesos percentuais dos seus respetivos subtemas. De facto, no âmbito da temática Democracia apenas dois subtemas foram associados a dimensões de populismo: Democracia: Geral (+) (cerca de 10,8\%) e Democracia Direta (+) (cerca de 10,3\%). A Democracia: Geral (+) corresponde a posições favoráveis à democracia enquanto método e/ou objetivo; apoio a diferentes partes do regime democrático (ex: Estado de Direito, Separação de Poderes, etc.); estímulo à participação política dos cidadãos. A Democracia Direta (+), por sua vez, integra posições favoráveis ao sistema de democracia direta (Ex: Referendos, Orçamentos participativos). São exemplos destas propostas como: "Facilitar a iniciativa legislativa dos cidadãos" (PS, 2019, p. 34) ou "Dar mais poder às cidadãs e aos cidadãos além das eleições, tornando mais acessivel a "Iniciativa Legislativa de Cidadãos" (LIVRE, 2019, p. 46).

As dimensões de populismo foram ainda identificadas nos conteúdos que se reportam a posições favoráveis relativamente à competência do partido proponente para governar e/ou desfavoráveis em relação à competência dos outros partidos para o fazer (Autoridade Política: Competência Partidária).

0 Populismo surge, de uma forma geral, integrado em referências desfavoráveis à constituição do país ou em posições favoráveis a reformas constitucionais (ex: "Esta Constituição foi imposta manu militarie desafiamos quem quer que seja a negá-Io (...)” (CHEGA, 2019, p. 5). É, ainda, considerável a associação do populismo a posições negativas em relação à União Europeia, nomeadamente dirigidas políticas específicas (ex: política agrícola comum; política monetária; contribuição dos Estados para o Orçamento da UE, etc.) ou às elites e instituições políticas europeias, como na declaração do BE “(...) se o país for colocado perante um ultimato das instituições europeias para impor novos programas de destruição da economia e dos direitos de quem aqui vive e trabalha, assumirá a defesa da democracia contra a chantagem, incluindo a mobilização dos poderes da soberania democrática e a desvinculação da União Monetária" (BE, 2019, p. 123).

Por outro lado, as temáticas em relação às quais o populismo surge associado com menor frequência são: a Regulação do Mercado (0,5\%), isto é, posições que visam a criação de um mercado económico aberto e justo, nomeadamente pelo combate a ações disruptivas do seu funcionamento (ex: monopólios, dumping, etc.) ou medidas para a proteção do consumidor e dos pequenos negócios face aos poderes das grandes empresas; a Descentralização (+) (0,5\%), isto é, posições favoráveis à descentralização do poder político e/ou económico (ex: princípio da subsidiariedade, municipalização, regionalização, etc.) e as Forças Armadas (-) (0,5\%), isto é, posições negativas em relação às forças armadas e/ou à sua atuação mas também posições favoráveis, nomeadamente, ao desarmamento, à redução de despesa neste setor ou até oposição à Organização do Tratado do Atlântico Norte (OTAN).

Uma análise global, porém, esbate diferenças importantes entre os partidos que apenas se observam quando os consideramos individualmente. Com efeito, tal como se apresenta no Quadro n. ${ }^{\circ} 4$, a área temática em que mais surgem dimensões de populismo é a Democracia. Nesta área temática abrangente, encontram-se posições que se inserem tanto no subtema Democracia: Geral (+) como no Democracia Direta (+). Estas são as temáticas mais salientes nos programas eleitorais da IL, do L, do PAN e do PS. Considerando os partidos com maior saliência de dimensões de populismo, verificamos que as temáticas frequentemente ligadas a populismo são 0 Constitucionalismo (-), no caso do CH, e a Autoridade Política, no caso do PCP. 


\section{Quadro . $^{0} 4$ - Áreas temáticas mais salientes e mais associadas a dimensões de populismo nos programas eleitorais às Legislativas de $\mathbf{2 0 1 9}$}

\begin{tabular}{|c|c|c|c|c|}
\hline Partidos & \multicolumn{2}{|r|}{ Áreas temáticas mais salientes } & \multicolumn{2}{|c|}{$\begin{array}{l}\text { Áreas temáticas mais } \\
\text { associadas a dimensões } \\
\text { de populismo (globalmente) }\end{array}$} \\
\hline \multirow{3}{*}{ PS } & $1 .^{\mathrm{a}}$ & Tecnologia e Infraestrutura & $1 .^{a}$ & Democracia \\
\hline & $2 .^{a}$ & $\begin{array}{l}\text { Economia Anti-crescimento } \\
\text { e Sustentabilidade }\end{array}$ & \multirow[t]{2}{*}{$2 .^{a}$} & \multirow[t]{2}{*}{ Modo de Vida Nacional (+) } \\
\hline & $3 .^{a}$ & Expansão do Estado Social & & \\
\hline \multirow{3}{*}{ PAN } & $1 .{ }^{\mathrm{a}}$ & Proteção Ambiental & \multirow{3}{*}{$1 .^{a}$} & \multirow{3}{*}{ Democracia } \\
\hline & $2 .^{a}$ & Expansão do Estado Social & & \\
\hline & $3 .^{a}$ & $\begin{array}{l}\text { Economia Anti-Crescimento } \\
\text { e Sustentabilidade }\end{array}$ & & \\
\hline \multirow{3}{*}{ PCP } & $1 .{ }^{\mathrm{a}}$ & Expansão do Estado Social & $1 .^{\mathrm{a}}$ & Autoridade Política \\
\hline & $2 .^{a}$ & Trabalhadores (+) & $2 .^{a}$ & União Europeia (-) \\
\hline & 3. ${ }^{\mathrm{a}}$ & Tecnologia e Infraestrutura & $3 .^{a}$ & Trabalhadores (+) \\
\hline \multirow{3}{*}{$\mathbf{L}$} & 1. ${ }^{\mathrm{a}}$ & Proteção Ambiental & $1 .^{a}$ & Democracia \\
\hline & $2 .^{a}$ & Expansão do Estado Social & $2 .^{a}$ & $\begin{array}{c}\text { Autoridade Política; } \\
\text { Liberdade e Direitos Humanos }\end{array}$ \\
\hline & $3 .^{a}$ & $\begin{array}{l}\text { Economia Anti-Crescimento } \\
\text { e Sustentabilidade }\end{array}$ & $3 .^{a}$ & $\begin{array}{l}\text { Corrupção Política; } \\
\text { Análise Marxista (+) }\end{array}$ \\
\hline \multirow{3}{*}{ BE } & $1 .^{\mathrm{a}}$ & Expansão do Estado Social & $1 .^{\mathrm{a}}$ & União Europeia (-); Democracia \\
\hline & $2 .^{a}$ & Igualdade (+) & $2 .^{a}$ & Autoridade Política \\
\hline & $3 .^{\mathrm{a}}$ & $\begin{array}{l}\text { Economia Anti-crescimento } \\
\text { e Sustentabilidade }\end{array}$ & $3 .^{a}$ & Igualdade (+) \\
\hline \multirow{6}{*}{ CDS-PP } & $1 .{ }^{\mathrm{a}}$ & Liberdade e Direitos Humanos & $1 .^{a}$ & Constitucionalismo (-) \\
\hline & $2 .^{a}$ & Lei e Ordem & $2 .^{a}$ & Liberdade e Direitos Humanos \\
\hline & $3 .^{a}$ & Limitação da Educação & $3 .^{a}$ & Autoridade Política \\
\hline & 1. ${ }^{\mathrm{a}}$ & Eficiência Administrativa e Governamental & \multirow{3}{*}{$1 .^{a}$} & \multirow{3}{*}{ Expansão do Estado Social } \\
\hline & $2 .^{a}$ & Incentivos Económicos (+) & & \\
\hline & $3 .^{a}$ & Tecnologia e Infraestrutura & & \\
\hline \multirow{3}{*}{ IL } & 1. ${ }^{\mathrm{a}}$ & Eficiência Administrativa e Governamental & $1 .^{\mathrm{a}}$ & Democracia \\
\hline & $2 .^{a}$ & Expansão da Educação & \multirow{2}{*}{$2 .^{a}$} & \multirow{2}{*}{ Autoridade Política } \\
\hline & $3 .^{a}$ & Economia de Livre Mercado & & \\
\hline \multirow{3}{*}{ PSD } & 1. ${ }^{\mathrm{a}}$ & Eficiência Administrativa e Governamental & $1 .^{\mathrm{a}}$ & Corrupção Política \\
\hline & $2 .^{a}$ & Tecnologia e Infraestrutura & \multirow{2}{*}{$2 .^{a}$} & \multirow{2}{*}{ Modo de Vida Nacional (+) } \\
\hline & $3 .^{\mathrm{a}}$ & Expansão do Estado Social & & \\
\hline
\end{tabular}


Comparando as três temáticas mais salientes em cada programa eleitoral com as três temáticas mais associadas a dimensões de populismo, verifica-se que, globalmente, não existe uma correspondência entre as duas variáveis. Considerando os nove partidos que apresentam alguma dimensão de populismo, concluímos que, apenas em três se regista alguma correspondência entre prioridades programáticas e áreas temáticas mais associadas a populismo - PCP, BE e CH (cf. Quadro n. ${ }^{\circ}$ 4). Para cada um destes partidos, e considerando as três áreas mais salientes, observa-se que apenas uma temática é comum quer na análise do programa eleitoral como um todo, quer na análise de populismo. Além disto, observa-se também que as temáticas em relação às quais se verificou haver correspondência variam entre os três partidos.

No caso do PCP, a temática comum é Trabalhadores (+), sendo que esta é a segunda temática mais saliente do programa do partido e a terceira mais associada às dimensões de populismo. No programa do $B E$, por outro lado, a Igualdade (+) surge como a segunda temática mais saliente e simultaneamente como a terceira mais associada a dimensões de populismo. Quanto ao $\mathrm{CH}$, é em relação à temática Liberdade e Direitos Humanos que encontramos uma correspondência, sendo que esta se afigura como a temática mais saliente no programa do partido e, concomitantemente, aparece como a segunda mais frequentemente associada a dimensões de populismo.

Note-se que a correspondência observada entre saliência temática e referências a alguma dimensão de populismo nos programas eleitorais surge em três dos partidos que revelaram maior grau de permeabilidade à ideologia populista, como vimos anteriormente. Ao mesmo tempo, estes são os partidos com representação parlamentar situados nos pontos mais extremos, quer à esquerda, quer à direita, do espectro político.

\section{Quadro n. $^{0} 5$ - Áreas temáticas mais associadas a cada dimensão de populismo por partido}

\begin{tabular}{|c|c|c|c|c|}
\hline \multirow{2}{*}{\multicolumn{2}{|c|}{ Partidos }} & \multicolumn{3}{|c|}{ Dimensões de Populismo } \\
\hline & & Anti-Elitismo & Povo Virtuoso & Soberania Popular \\
\hline \multirow{5}{*}{$\begin{array}{l}\text { 똥 } \\
\text { 롶 } \\
\text { 离 }\end{array}$} & PS & & & Democracia \\
\hline & PAN & & & Democracia \\
\hline & PCP & União Europeia (-) & $\begin{array}{l}\text { Trabalhadores (+) e } \\
\text { Autoridade Política }\end{array}$ & Democracia e Autoridade Política \\
\hline & $\mathbf{L}$ & Autoridade Política & Democracia & Democracia \\
\hline & BE & União Europeia (-) & $\begin{array}{c}\text { Igualdade (+) e } \\
\text { Autoridade Política }\end{array}$ & Democracia \\
\hline \multirow{4}{*}{ 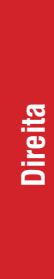 } & $\mathrm{CH}$ & Constitucionalismo (-) & $\begin{array}{c}\text { Liberdade e } \\
\text { Direitos Humanos }\end{array}$ & Constitucionalismo (-) \\
\hline & CDS-PP & Expansão do Estado Social & & \\
\hline & IL & Autoridade Política & Democracia & Democracia \\
\hline & PSD & Corrupção Política & Modo de vida Nacional (+) & \\
\hline
\end{tabular}


Por outro lado, atendendo à relação entre as principais dimensões de populismo e áreas temáticas a elas associadas, distinguem-se alguns padrões entre os partidos. A dimensão antielitista do populismo dos partidos de esquerda radical incide principalmente sobre questões relacionadas com a União Europeia, enquanto nos partidos de direita se destacam os temas relacionados com a competência das elites partidárias para governarem. Por outro lado, o Anti-Elitismo do L e da IL é, sobretudo, dirigido às elites nacionais.

A esquerda radical partilha também o facto de relacionar a temática da Autoridade Política com a dimensão Povo Virtuoso. Quanto à Soberania Popular, com exceção do Chega, todos os partidos a associam mais frequentemente à temática da democracia, nomeadamente a propostas favoráveis a mecanismos de democracia direta e participativa, como referendos e a iniciativa legislativa de cidadãos.

\section{Conclusão}

Este artigo procurou compreender em que medida os partidos políticos portugueses se revelaram permeáveis ao populismo nos seus programas eleitorais às Legislativas de 2019. Além disso, pretendia-se dar a conhecer a relação existente entre a saliência de dimensões de populismo e as áreas temáticas mais destacadas pelos partidos políticos. Até 2019, a tese dominante apontava Portugal como uma exceção no contexto europeu, destacando-o pela sua impermeabilidade face ao populismo de direita. Este estudo refuta parcialmente esta tese, demonstrando que a partir de 2019, o sistema partidário se tornou mais permeável ao populismo, especialmente ao populismo de direita. Este passou a ser corporizado pelo partido CHEGA, partido de direita radical e antissistema que, pela primeira vez, obtém representação parlamentar.

Quanto aos partidos de esquerda radical, observa-se que o PCP, o L e o BE são os partidos que mais fazem apelos populistas. Estes resultados encontram-se respaldados pela literatura internacional que correlaciona positivamente 0 grau de radicalismo ideológico dos partidos com a sua adesão ao populismo, mas também pela literatura nacional que consistentemente tem defendido esta tendência geral em relação aos partidos de esquerda radical. Pelo contrário, comparativamente, os partidos mainstream e ideologicamente moderados revelam-se menos porosos à retórica populista em 2019, mantendo o padrão já identificado em estudos anteriores.

Este estudo constitui, além disso, um contributo inovador para o avanço no conhecimento do populismo em Portugal ao debruçar-se sobre uma questão praticamente inexplorada até agora: a relação entre populismo e outras posições políticas. Globalmente, observamos que o populismo surge mais frequentemente associado a temas como a democracia, a autoridade política, a Constituição Portuguesa, a União Europeia e a corrupção política, respetivamente.

A democracia é o tema mais mobilizado nos apelos populistas da IL, do L, do PAN e do PS, sendo que, de um modo geral, estes se relacionam, em alguma medida, com a dimensão do populismo da Soberania Popular. Por outro lado, os partidos com maior incidência de apelos populistas - CH e PCP - preferem relacioná-Ios com posições negativas em relação à Constituição e favoráveis à sua alteração $(\mathrm{CH})$ ou com posições negativas em relação à atuação, elites, políticas da União Europeia (PCP). A análise discriminada de cada dimensão de populismo permite também uma leitura pormenorizada das associações entre dimensões de populismo e saliência temática. 
As interpretações e ilações sobre os nossos resultados devem ter em consideração que este estudo circunscreve a sua análise aos conteúdos dos programas eleitorais dos partidos que obtiveram representação parlamentar em 2019, encontrando-se, por isso, limitado temporal e contextualmente a este ciclo eleitoral. Este estudo encontra-se em harmonia com trabalhos anteriores ao demonstrar que a saliência de populismo em programas eleitorais é bastante reduzida. Considerando as caraterísticas atribuídas quer aos partidos populistas quer às suas lideranças, parece provável que a análise de discursos orais, como discursos de campanha ou debates eleitorais, em que ocorre uma interação direta entre os atores políticos e o público-alvo, revele uma maior saliência de apelos populistas. A investigação futura sobre populismo deve expandir a análise de conteúdo a fontes alternativas aos programas eleitorais.

Por fim, consideramos que o estudo do populismo e das suas relações com outras posições partidárias através da abordagem do MARPOR abre caminho para a possibilidade de permitir não só realizar análises comparativas e longitudinais entre países, mas também assegurar um maior grau de fiabilidade dos seus resultados.

\section{Bibliografia}

Abreu, Alexandre, Mendes, Hugo, Rodrigues, João, Gusmão, José Guilherme, Serpa, Nuno, Teles, Nuno, Alves, Pedro Delgado, \& Mamede, Ricardo Paes. (2013). A Crise, a Troika e as Alternativas Urgentes. Lisboa: Tinta da China.

Bakker, Ryan, Hooghe, Liesbet, Jolly, Seth, Marks, Gary, Polk, Jonathhan, Rovny, Jan, Steenbergen, Marco, \& Vachudova, Milada Anna. (2020). 1999-2019 Chapel Hill Expert Survey Trend File - Version 1.2. Retirado de www.chesdata.eu.

Bloco de Esquerda (BE). (2019). Programa Eleitoral, Legislativas 2019, Bloco de Esquerda. Lisboa.

Bobba, G., \& McDonnell, D. (2016). "Different Types of Right-Wing Populist Discourse in Government and Opposition: The Case of Italy". South European Society and Politics, 21(3), 281-299.

Bonikowski, B. (2017). "Ethno-Nationalist Populism and the Mobilization of Collective Resentment". The British Journal of Sociology, 68(1), 181-213.

Bonikowski, B., Halikiopoulou, Daphne, Kaufmann, Eric, \& Rooduijn, Matthijs. (2019). "Populism and nationalism in a comparative perspective: a scholarly exchange". Nations and Nationalism, 25(1), 58-81.

Bosco, A., \& Morlino, L. (2006). "What Changes in South European Parties? A Comparative Introduction". South European Society and Politics, 11(3-4), 331-358.

Cachafeiro, M., \& Plaza-Colodoro, C. (2018). "Populist Euroscepticism in Iberian party systems". Political Studies Association, 38(3), 344-360.

Canovan, M. (1981). Populism. New York and London: Harcourt Brace Jovanovich.

Canovan, M. (1999). "Trust the People! Populism and the Two Faces of Democracy". Political Studies, 47, 2-16. Carreira da Silva, F., \& Salgado, S. (2018). "Why no populism in Portugal?", in M. C. Lobo, F. Carreira da Silva, \& J. P. Zúquete (Eds.), Changing societies: legacies and challenges. Vol. 2. Citizenship in crisis (pp. 249-268). Lisboa: ICS. 
Carreira da Silva, F., \& Vieira, M. B. (2019). "Populism as a logic of political action". European Journal of Social Theory, 22(4), 497-512.

Charaudeau, P. (2016). "Du discours politique au discours populiste. Le populisme est-il de droite ou de gauche? ", in F. Corcuera et al. (Dir.), Les discours politiques. Regards croisés (pp. 2-43). Paris: L'Harmattan.

Chega. (2019). Programa politico, Legislativas 2019, CHEGA. Lisboa.

Cleen, B. de. (2018). "Populism, Exclusion, Post-truth. Some Conceptual Caveats; Comment on The Rise of Post-truth Populism in Pluralist Liberal Democracies: Challenges for Health Policy". IJHPM, 7(3), 268-271.

Deegan-Krause, K., \& Haughton, T. (2009). "Toward a More Useful Conceptualization of Populism: Types and Degrees of Populist Appeals in the case of Slovakia”. Politics \& Policy, 37(4), 821-841.

Eatwell, R., \& Goodwin, M. (2019). Populismo. Porto Salvo: Desassossego.

Fagerholm, A. (2016). "Ideology: A proposal for a conceptual typology". Social Science Information, 55(2), 137-160.

Ferreira, R A. (2016). "A evolução das ideologias políticas do PSD e do CDS-PP: Uma análise dos documentos programáticos (1974-2012)", in Riccardo Marchi, As direitas na democracia portuguesa. Origens, Percursos, Mudanças e Novos Desafios. Alfragide: Texto Editores.

Gabel, M., \& Huber, J. (2000). "Putting Parties in Their Place: Inferring Party Left-Right Ideological Positions from Party Manifestos Data". American Journal of Political Science, 44(1), 94-103.

Gallie, W.B. (1956). "Essentially Contested Concepts: Proceedings of the Aristotelian Society", New Series, 56(1955-1956), 167-198.

Gidron, N., \& Bonikowski, B. (2014). "Varieties of Populism: Literature Review and Research Agenda". SSRN Electronic Journal, 13, 0-38.

Giorgi, Elisabetta de, \& Santana-Pereira, José. (2020). "The Exceptional Case of Post-Bailout Portugal: A Comparative Outlook". South European Society and Politics, 25(2), 127-150.

Giorgi, Elisabetta de, \& Santana-Pereira, José. (2021). "Still different? Reassessing Portuguese exceptionalism within southern Europe". LSE European Politics and Policy. Retirado de http://eprints.Ise.ac.uk/109109/.

Hawkins, K. A., Aguilar, Rosario, Silva, Bruno Castanho, Jenne, Erin K., Kocijan, Bojana, \& Kaltwasser, Cristóbal Rovira. (2019). "Measuring Populist Discourse: The Global Populism Database". Paper Presented at the 2019 EPSA Annual Conference in Belfast, UK, June 20-22, p. 1-16.

Jalali, Carlos, Moniz, João, \& Silva, Patrícia. (2020). "In the Shadow of the 'Government of the Left': The 2019 Legislative Elections in Portugal". South European Society and Politics, 25(2), 229-255.

Krouwel, A. P. M., \& Van Elfrinkhof, A. M. E. (2014). "Combining strengths of methods of party positioning to counter their weaknesses: the development of a new methodology to calibrate parties on issues and ideological dimensions". Quality and Quantity, 48(3), 1455-1472.

Laclau, E. (2005). "Populism: What's in a Name?", in Francisco Panizza, Populism and the Mirror of Democracy. London. New York: Verso. 
Lisi, M. (2011). Os Partidos Políticos em Portugal: Continuidade e Transformação. Coimbra: Edições Almedina, S. A.

Lisi, M., \& Borghetto, E. (2018). "Populism, Blame Shifting and the Crisis: Discourse Strategies in Portuguese Political Parties". South European Society and Politics, 23(4), 405-427.

Lisi, M., Llamazares, I., \& Tsakatika, M. (2019). "Economic crisis and the variety of populist response: evidence from Greece, Portugal and Spain". West European Politics, 42(6), 1284-1309.

Livre, 2019 - Programa para as Eleições Legislativas de 2019, LIVRE. Lisboa.

Loew, N., \& Faas, T. (2019). "Between Thin-and Host-ideologies: How Populist Attitudes Interact with Policy Preferences in Shaping Voting Behaviour”. Representation, 55(4), 493-511.

Manucci, L., \& Weber, E. (2017). "Why The Big Picture Matters: Political and Media Populism in Western Europe since the 1970's". Swiss Political Science Review, 23(4), 313-334.

March, L. (2007). "From Vanguard of the Proletariat to Vox Populi: Left-Populism as 'Shadow' of Contemporary Socialism". SAIS Review of International Affairs, 27(1), 63-77.

Marchi, Riccardo. (2016). As direitas na democracia portuguesa. Origens, Percursos, Mudanças e Novos Desafios. Alfragide: Texto Editores.

Marchi, Riccardo. (2020). A Nova Direita Anti-Sistema. 0 Caso do Chega. Lisboa: Edições 70.

Martin, G. (2012). "The Socialist-Populist Ideology I: From Patrice Lumumba to Samora Machel”, in G. Martin, African Political Thought (pp. 71-129).

Martinelli, A. (Ed.). (2018). When Populism Meets Nationalism: Reflections on Parties in Power. Ledizioni.

Meijers, M. J., \& Zaslove, A. (2021). "Measuring Populism in Political Parties: Appraisal of a New Approach". Comparative Political Studies, 54(2), 372-407.

Moreau, P. (2018). "Le national-populisme en Autriche et en Allemagne: approche comparative de l'AfD et du FPÖ". Revue d'Allemagne et des pays de langue allemande, 50(1), 159-182.

Mouffe, C. (2002). "La fin du politique et le défi du populisme de droite". Revue Du Mauss, 20(2), 178-194.

Mouffe, C. (2018). Por um Populismo de Esquerda. Lisboa: Gradiva.

Mudde, C. (2004). "The Populist Zeitgeist". Government and Opposition, 39(4), 541-563.

Mudde, C. (2007). Populist Radical Right Parties in Europe. Cambridge: Cambridge University Press.

Mudde, C., \& Kaltwasser, C. Rovira. (2012). "Exclusionary vs. Inclusionary Populism: Comparing Contemporary Europe and Latin America". Government and Opposition, 48(2), 147-174.

Mudde, C., \& Kaltwasser, C. Rovira. (2017). Populismo - Uma Brevíssima Introdução. Lisboa: Gradiva.

Panizza, F. (2005). Populism and the Mirror of Democracy. London: Verso.

Partido Socialista (PS). (2019). Programa Eleitoral, Legislativas 2019, PS. Lisboa.

Pinto, A. C., \& Teixeira, C. P. (2019). "Portugal Before and After the 'Great Recession': A Resilient Democracy?", in A. C. Pinto; C. P. Teixeira (Eds.), Political Institutions and Democracy in Portugal: Assessing the Impact of the Eurocrisis (pp. 1-12). 
Quintas da Silva, R. (2018). "A Portuguese exception to right-wing populismo". Palgrave Communications, 4(1), 1-5.

Ramiro, L., \& Gomez, R. (2017). "Radical-Left Populism during the Great Recession: Podemos and Its Competition with the Established Radical Left". Political Studies, 65(1), 108-126.

Rooduijn, M. (2019). "State of the field: How to study populism and adjacent topics? A plea for both more and less focus". European Journal of Political Research, 58(1), 362-372.

Rooduijn, M., \& Akkerman, T. (2017). "Flank attacks: Populism and left-right radicalism in Western Europe. Party Politics, 23(3), 193-204.

Rooduijn, M., \& Pauwels, T. (2011). "Measuring populism: Comparing two methods of content analysis". West European Politics, 34(6), 1272-1283.

Rose, R., \& Mackie. T. T. (1988). "Do Parties Persist or Fail? The Big Trade-Off Facing Organizations", in Key Lawson, P. Merkl (Eds.), When Parties Fail: Emerging Alternative Organizations. Princeton, NJ: Princeton University Press.

Rousseau, J. J. (1981). 0 Contrato Social. Mem Martins: Europa-América.

Salgado, S. (2019). "Where's populism? Online media and the diffusion of populist discourses and styles in Portugal". European Political Science, 18(1), 53-65.

Schmitter, C. P., \& Karl, L. T. (1991). "What Is Democracy Is...And Is Not”. Journal of Democracy, 2(3), 75-88. Stavrakakis, Y., \& Katsambekis, G. (2014). "Left-wing populism in the European periphery: the case of SYRIZA". Journal of Political Ideologies, 19(2), 119-142.

Taggart, P. (2000). Populism. Buckingham: Open University Press.

Tocqueville, A. (2002). Democracy in America. Disponível em https://seas3.elte.hu/coursematerial/ LojkoMiklos/Alexis-de-Tocqueville-Democracy-in-America.pdf.

Valle, A. (2021). Populismo nos programas eleitorais dos partidos portugueses para as legislativas de 2019: uma questão de grau? (Dissertação de Mestrado). Disponível em https://www.iscte-iul.pt/tese/10524.

Van Spanje, Joost. (2010). "Contagious Parties: Anti-Immigration Parties and their Impact on Other Parties Immigration Stances in Contemporary Western Europe". Party Politics, 16(5), 563-586.

Weyland, K. (2003). "Latin American Neopopulism”. Third World Quarterly, 24(6), 1095-1115. 